\title{
Review: Characterization and Role of Grape Solids during Alcoholic Fermentation under Enological Conditions
}

\author{
Erick Casalta, ${ }^{1 *}$ Aude Vernhet, ${ }^{1}$ Jean-Marie Sablayrolles, ${ }^{1}$ Catherine Tesnière,${ }^{1}$ \\ and Jean-Michel Salmon ${ }^{2}$
}

\begin{abstract}
During wine production, grape solids have a large impact on the fermentation characteristics and organoleptic qualities of the resulting wine. Here we review the research on grape solids. We begin by focusing on the origin, physical characteristics, and composition of these solids and on the changes in these factors that occur during fermentation. We then consider the impact of solids on fermentation, the role of sterols, the control of solids, and interactions between solids and other nutrients. Solids exert their effects on alcoholic fermentation mainly by modulating lipid supply. The balance between solids content and nitrogen is a key factor in fermentation control. The study of grape solids is in its infancy and requires further development. Knowledge of the composition of these solids and of sterol uptake mechanisms by yeast should facilitate improvements in fermentation control.
\end{abstract}

Key words: alcoholic fermentation, grape solids, sterols, yeast

During red wine processing, alcoholic fermentation occurs in both the liquid and solid phases of the must. Maceration of solid phases helps extract polyphenols from the pomace. In white wine production, alcoholic fermentation is limited to the liquid phase. The two phases are separated by pressing before and after the alcoholic fermentation for white and red wines, respectively. The introduction of new practices into red winemaking (e.g., thermovinification, flash release, and centrifuge decanting) has made it possible to carry out fermentations in the liquid phase at low temperature and without maceration. These new technological advances include the treatment of the harvested grapes with heat, followed by the pressing of the must before alcoholic fermentation, as is done for white wines.

Thermovinification and flash release help extract polyphenols before alcoholic fermentation, yielding light, fruity wines. In both systems, pressing eliminates the pomace, but many solid particles still remain in the liquid phase. These solids of various sizes, generally referred to as "sludge," are then removed by clarification before fermentation. Several clarification methods are used (Battle et al. 1998): cold settling, filtration, centrifugation, and flotation. In some cases, clarification problems arising from polysaccharides produced by grapewine mold diseases such as gray mold can occur, but these problems will not be discussed here.

${ }^{1}$ INRA, UMR 1083, Science for Enology, bat. 28, 2 place Viala, F34060 Montpellier, France; and ${ }^{2}$ INRA, UE 999, Experimental Unit of Pech Rouge, F11430 Gruissan, France.

*Corresponding author (casalta@supagro.inra.fr)

Acknowledgments: The authors wish to thank M. Bes and E. Aguéra from the INRA Experimental Unit of Pech Rouge (Gruissan, France) for helpful discussions and advice.

Manuscript submitted Jun 2015, revised Sept 2015, Oct 2015, accepted Oct 2015

Copyright (C) 2016 by the American Society for Enology and Viticulture. All rights reserved.

doi: 10.5344/ajev.2015.15060
Solid particles are widely considered suppliers of nutrients useful for fermentation (Ribéreau-Gayon 1985). These nutrients include lipids, and the principal lipid components of eukaryotic membranes are phospholipids, sterols, sphingolipids, and glycerolipids. These molecules play a key role in maintaining cell membrane integrity. Therefore, lipids are key determinants of the growth, metabolism, and viability of yeasts during alcoholic fermentation. Particularly in the forms of phytosterols and fatty acids, lipids are a major source of nutrients for fermenting yeasts (Ribereau-Gayon et al. 1975). Because of their strong hydrophobicity, the lipids in grape must are mostly provided by the solid particles. In contrast to the role of assimilable nitrogen, which has been extensively studied in alcoholic fermentation, the effect of solid particles on fermentation kinetics and yeast metabolism has received little attention even though enological experience suggests that the amount of these particles in grape musts affects fermentation kinetics and wine quality.

This review provides an overview of the research on grape solids, focusing on the latest developments in solid-particle characterization and on the management of these particles during enological alcoholic fermentation. We first provide an overview of the current knowledge about the characteristics of solid particles; we then discuss the role of sterols in yeast metabolism; and last, we highlight the role of solid particles during alcoholic fermentation in white wine production, and its implications for fermentation control.

\section{Grape Solids}

Origin and physical characteristics. Sludge consists of suspended solids (mostly cell fragments) present in white or red grape juices after pressing. The characteristics and quantities of these grape solids in juices vary considerably and depend on the raw material and the process used for juice extraction. The intensity of the mechanical crushing forces applied to the berries depends on the juice extraction method, 
which also controls the degree of filtration and retention of solid debris from the pomace. Treatment of red grapes by flash release or thermovinification, followed by pressing and liquid-phase fermentation, increases the extraction of polyphenols and polysaccharides, affecting the amount of extracted suspended material and its characteristics. This winemaking process specific to red wines results in red grape juices that are more turbid than white grape juices.

In winemaking, the grape solids present in juice are most commonly characterized by measuring turbidity and the total wet or dried suspended solids (TWSS or TDSS, respectively, expressed as $\%[\mathrm{w} / \mathrm{w}])$. In red musts, turbidity generally ranges from 1000 to 5000 nephelometric turbidity units (NTU), and TWSS range from 1.5 to $5 \mathrm{~g} / 100 \mathrm{~g}$. These parameters are useful and easily accessible to winemakers, but they provide no information about the nature and composition of the suspended solids or their potential impact on fermentation. In addition, there is no simple and direct relationship between turbidity and TWSS (Vernhet et al. in press). Indeed, turbidity does not only depend on the suspended solid fraction, but also on particle size, shape, and refractive index. Thus, depending on the nature and the sizes of suspended solid material, similar quantities can result in different turbidities (Davies-Colley and Smith 2001).

The particle size distribution of suspended solids has been studied by light scattering in several red musts obtained from various grape varieties by different heating (i.e., flash release and thermovinification) and extraction processes. Particles with a wide range of sizes (up to several hundred micrometers) were detected, but most of the particles had micronic and submicronic hydrodynamic diameters $(<2 \mu \mathrm{m})$. Large particles accounted for only a small fraction of the total suspended solids. These results are consistent with those obtained for a white must in a study based on impedance measurements with a Coulter counter in which $92 \%$ of particles were observed to have a hydrodynamic diameter in the range indicated above (Davin and Sahraoui 1993).

Composition. Little is known about the precise nature and composition of grape solids. Analyses on small particles fractionated by static settling from a white must showed these particles to have the following overall composition (as percentage of dry weight): $72 \%$ total sugars, $8 \%$ lipids, $5.5 \%$ minerals, $5.2 \%$ pectins, and $\sim 2.6 \%$ nitrogen (Alexandre et al. 1994). On the basis of this overall composition and sugar content, the authors concluded that the solid particles present in white musts consisted mostly of cell wall fragments. The lipids present contained $52.7 \%$ unsaturated fatty acids (UFAs) (25\% linoleic acid, 22.2\% oleic acid, and 5.5\% palmitoleic acid) and $47.1 \%$ saturated fatty acids (SFAs) (25\% palmitic acid, 13.8\% stearic acid, and 8.3\% lauric acid) (Alexandre et al. 1994). In grapevine berries at maturity, the concentrations of UFAs and SFAs differ (72 and 28\%, respectively) (Roufet et al. 1987). The grape skin represents an important source of fatty acids, with a 1.5 to 3 times higher fatty acid content in this tissue than in pulp (Roufet et al. 1987).

In solids from white and red musts, phytosterol concentrations range from 3 to $10 \mathrm{mg}$ cholesterol equivalent per gram dry weight, and their composition is as follows: $89 \%$ $\beta$-sitosterol, $6 \%$ campesterol, 3\% stigmasterol, and 3\% stigmastanol (Casalta, unpublished observations, 2015). This composition closely resembles that of berry skins, as reported by Le Fur et al. (1994). $\beta$-Sitosterol has been shown to be the most abundant phytosterol component of both the flesh and skin of grape berries (Ruggiero et al. 2013).

Similar composition analyses, coupled with transmission electron microscopy (TEM), were performed on small suspended solids from red musts. The TEM observations provided evidence suggesting that the small particles in red musts consist mostly of cell cytoplasm fragments, such as membranes of various origins, chloroplasts, and tannosomes (Brillouet et al. 2013), and of numerous amorphous and more or less spherical structures potentially corresponding to modified organelles or molecular or macromolecular aggregates. Contrary to expectations, insoluble cell wall fragments either were not present or did not account for a significant proportion of these fine particles. These particles were found to have the following average composition: $5.6 \%$ nitrogen, $13 \%$ lipids, 9 to $12 \%$ tannins, 0.3 to $1.2 \%$ anthocyanins, 6 to $9 \%$ neutral sugars, and 3\% ashes (Vernhet et al. in press). This composition differed from that of the small suspended solids in white musts. The principal differences were a much smaller amount of carbohydrates, a much higher amount of proteins, and the presence of polyphenols, including tannins in particular, in red musts.

The possible presence of polyphenols in suspended solids in white musts has also not been checked. Although much lower amounts of polyphenols are expected in white than in red musts, this should be confirmed because of the potential impact of polyphenols on overall wine quality. Neutral sugars of small suspended solids in red musts were analyzed by gas chromatography after trifluoroacetic acid or Saeman hydrolysis (Harris et al. 1984, Saeman et al. 1954) and after the conversion of monosaccharides into their alditol acetate derivatives. Most of the polysaccharides present in these fine particles originated from water-soluble pectic polysaccharides rather than from insoluble cell wall fragments, consistent with TEM observations.

Neutral sugar analyses can provide useful information about the nature of the polysaccharides associated with small particles, but such analyses do not take into account the acidic sugars accounting for 30 to $40 \%$ of soluble cell wall polysaccharides in grape. The total sugar content is therefore underestimated in these analyses. It has been suggested that these soluble polysaccharides are present in suspended solids because of their involvement in aggregation with tannins or proteins or their adsorption onto other suspended particles. The presence of proteins and tannins in suspended solids is consistent with that of cell fragments and organelles, such as membrane fragments and tannosomes, in these solids. In addition, proteins and tannins are probably present as amorphous aggregates or adsorbed on cell fragments. Besides their propensity to interact with proteins, tannins tend to adsorb at interfaces. This phenomenon is well known and has been studied in enology in different contexts, including interactions 
of tannins with polymers or grape cell walls (Cartalade and Vernhet 2006, Hanlin et al. 2010, Bindon et al. 2010).

Aggregation phenomena are likely to be more frequent in red grape juices than in those of white grapes because of the simultaneous presence of proteins and tannins in red musts. This could explain the higher amount of proteins in suspended solids of red musts. An analysis of lipids present in small particles by thin-layer chromatography revealed that these lipids consisted of apolar sterols, diacylglycerides and triacylglycerides, and polar phospholipids and glycolipids (i.e., steryl glycosides and esterified steryl glycosides).

Changes in solids during fermentation. Few studies have investigated the changes in solids during enological alcoholic fermentations. Casalta et al. (2009) showed that the physical behavior of the sludge particles depends on the $\mathrm{CO}_{2}$ production by the yeast during white winemaking. This study also showed that solid-particle dynamics could be divided into three phases clearly linked to the fermentation activity of the yeast. The first phase corresponds to the lag phase and thus to the earliest part of the growth phase. Solids rapidly settle at the bottom of the tank during the first hour, resulting in a large decrease in turbidity. The second phase corresponds to the main part of the growth phase. Medium- and large-size solid particles (i.e., those with a diameter exceeding $\sim 1 \mu \mathrm{m}$ ) break up into smaller particles (of 0.1 to $0.2 \mu \mathrm{m}$ in size), probably because of strong agitation mediated by the bubbling of $\mathrm{CO}_{2}$. Indeed, both the mediumsize and large particles were found to consist of several small aggregated particles. At this point in the fermentation, the solids are dispersed in the medium, and any deposits rapidly disappear.

The third phase is completed during the stationary phase. Some of the small particles reaggregate, leading to the appearance of new medium-size and large particles, which then deposit with the yeast lees at the bottom of the tank. At the end of this last phase, the solids become more compacted, decreasing the height of the layer of the sediment. Changes in must turbidity during the fermentation are thus much more complex than expected: the solids are completely dispersed during fermentation, but mean turbidity never reaches its initial levels. Initial turbidity cannot, therefore, be considered representative of solid-particle dynamics.

\section{Effects of Solids on Fermentation}

Role of sterols and UFA in yeasts. Solids are an important source of nutrients for yeasts during fermentation, principally because of their nonsoluble grape phytosterol content (Luparia et al. 2004). They compensate, at least partially, for deficiencies in both oxygen (Andreasen and Stier 1953) and long-chain fatty acids (Cabanis and Flanzy 1998). At the start of the alcoholic fermentation, they are required for yeast growth, with 2 to $4 \mathrm{mg}$ phytosterols/L required for maximal growth (Deytieux et al. 2005). These molecules subsequently enable the yeasts to tolerate high ethanol concentrations, and they decrease the risks for sluggish and stuck fermentations. They play a key role in yeast metabolism, which has been described in detail elsewhere.
In the presence of oxygen, yeast cells can de novo synthesize their own major sterol, ergosterol, in the membrane of the endoplasmic reticulum and transport it to the plasma membrane. In the absence of oxygen, cells take up sterols from the environment and transport the lipids back into the membrane of the endoplasmic reticulum, where free sterols become esterified and are stored in lipid droplets. Steryl ester formation thus provides a good indicator for assessing the retrograde transport of endogenous sterols from the plasma membrane to the endoplasmic reticulum (Jacquier and Schneiter 2012). However, stigmasterol is directly incorporated into the plasma membrane in its free form (Luparia et al. 2004), and steryl esters are the main components of yeast lipid particles (Leber et al. 1994).

Sterol uptake in yeast is a multistep process. It involves interaction between external sterols and the cell wall, the incorporation of sterol into the plasma membrane, and its subsequent integration into the intracellular membranes for turnover. The sorting of sterols and their transport between membranes remain poorly understood, but both vesicular and nonvesicular pathways appear to be involved in these processes. In one such pathway in Saccharomyces cerevisiae, exogenous sterols are transported from the plasma membrane to the endoplasmic reticulum.

Yeasts do not take up exogenous sterol under aerobic conditions, but they are auxotrophic for sterol in the absence of oxygen (Fornairon-Bonnefond et al. 2002). Uptake assays have shown that 16 genes are required for sterol uptake, transport, and esterification (Reiner et al. 2005), and it has been suggested that incorporation into the plasma membrane is an early step in sterol uptake (Reiner et al. 2006). Preliminary studies have reported some of the physiological properties and effects of sterols on aerobic metabolism (Smith and Parks 1993, 1997), cell cycle completion (Dahl et al. 1987), sterol uptake (Lorenz et al. 1986), and sterol transport (Tuller and Dam 1995).

Sterols are essential lipid components of yeast cell membranes and are responsible for ensuring their integrity. Many studies have shown that sterols are important regulators of membrane permeability and fluidity (Daum et al. 1998), and that these molecules also play a key role in plasma membrane $\mathrm{H}^{+}$-ATPase activity. In addition, they regulate the cellular metabolic cycle in aerobic conditions and exogenous sterol uptake (Daum et al. 1998). Moreover, the sterol pathway appears to significantly contribute to oxygen consumption of cells under anaerobic conditions (Rosenfeld et al. 2003). Yeast growth in the absence of both anaerobic growth factors (sterols and fatty acids) and oxygen leads to the accumulation of large amounts of squalene in membranes, resulting in extremely low cell viability (Jollow et al. 1968, Jahnke and Klein 1983, Fornairon-Bonnefond et al. 2002).

UFAs are also important in yeast metabolism. The UFAto-SFA ratio is important for maintaining the membrane fluidity at low temperature. In the absence of oxygen, yeast cannot synthetize UFAs, and solids may be a source for them. Yeast cells uptake fatty acids with subsequent rapid incorporation into glycerolipids. The uptake kinetics observed are 
consistent with a dual mode of transport: one is a saturable, energy-independent process suggestive of a carrier-mediated transport, and the other is apparently a simple diffusion that predominates at high substrate concentrations. (Kohlwein and Paltauf 1984). During grape maturation, changes in the levels of fatty acids are small, except for linolenic acid, which decreases consistently (Roufet et al. 1987), a loss that was detected in both neutral and glycolipid fractions.

Control of solids. Given the impact of solids both on the fermentation itself and on the characteristics of the wine produced, the degree of grape juice clarification required depends on the objectives of the winemaker. There are several reasons for clarifying white grape juices before fermentation: (1) a large proportion of oxidative enzyme activities (plant cell-derived polyphenol oxidases or mold laccases), which could deplete the must of oxygen, and of elemental sulfur and other vineyard residues (sources of the $\mathrm{H}_{2} \mathrm{~S}$ produced by yeasts during fermentation) are associated with pulp and skin fragments, and (2) some evidence suggests that grape tissues contain an esterase that limits the accumulation of esters produced by the yeast during fermentation (Boulton et al. 1996).

However, several studies (Ribéreau-Gayon 1985, Houtman and du Plessis 1986, Feuillat et al. 1989) have reported some negative effects of excessive must clarification. In addition to its effect on yeast nutrition, sludge may have a physical effect on fermentation by favoring $\mathrm{CO}_{2}$ nucleation (Groat and Ough 1978, Axcell et al. 1988). Dissolved $\mathrm{CO}_{2}$ can be adsorbed onto fine particles at specific nucleation sites at which the $\mathrm{CO}_{2}$ bubbles increase in size before being released from the particle as free bubbles (Kühbeck et al. 2007). This mechanism decreases the concentration of dissolved $\mathrm{CO}_{2}$ in the liquid phase, thereby decreasing its toxic effects on the yeast (Jones and Greenfield 1982). Nevertheless, Casalta et al. (2012) have shown that the effects of sludge on alcoholic fermentation result principally from the provision of lipids. These authors compared alcoholic fermentation in a highly clarified must without solids with that of the same must supplemented with solids depleted of lipids and reported that yeast growth and fermentation kinetics were very similar in both of these musts.

Turbidity is the principal criterion used by enologists to evaluate the level of clarification. For white wine production, it is usually recommended to maintain turbidity at a sufficiently high level (50 to $150 \mathrm{NTU}$ ) to ensure that the lipid requirements of the yeast are met (Charrier et al. 2013). It should also be stressed that the use of new clarifying technologies, such as centrifuge decanters, rather than classical pressing systems, leads to the production of smaller solid particles during red and white or rosé winemaking, presumably providing the yeast with better access to nutrients during fermentation (Eudier et al. 2011, Duquene et al. 2014).

Interaction between solids and other nutrients. In their role as lipid suppliers, solids interact with other nutrients, including oxygen and in particular assimilable nitrogen (i.e., amino acids and ammonium, nitrogen being considered a nongaseous nutrient). Oxygen is involved in the ergosterol metabolic pathway, and oxygen addition is therefore one of the best ways to compensate for lipid deficiencies in yeasts. Sablayrolles and Barre (1986) estimated oxygen requirements of $\sim 10 \mathrm{mg} / \mathrm{L}$ in the absence of lipids in the must. The timing of oxygen addition is at least as important as the amount added. Oxygen is most effective when added at the end of the growth phase (Sablayrolles and Barre 1986, Vivas and Cros 1991), when the yeasts have used up their free and stored lipids. Another advantage of adding oxygen at this later stage is that this timing limits the risk for oxygen use by polyphenol oxidases. Indeed, oxygen consumption by oxidases is probably much less effective than oxygen assimilation by yeasts at this time point than at the inoculation stage.

Assimilable nitrogen is generally considered to be the principal limiting nutrient in winemaking fermentations (Bely et al. 1990). However, Casalta et al. (2012) showed that, in white winemaking, grape solids or optimized oxygen additions were required for complete consumption of the assimilable nitrogen present in the must. In the absence of these solids, the lipid stock of the inoculating yeast is diluted excessively, preventing the yeast from incorporating nitrogen. Such conditions are associated with higher cell mortality and a greater risk for stuck fermentation. At higher assimilable nitrogen content, larger quantities of grape solids are required. These data highlight the importance of taking into account the balance between assimilable nitrogen and lipids in the control of white wine production (Casalta et al. 2013, Tesnière et al. 2013).

\section{Conclusion}

This review highlights the key role of solid particles during alcoholic fermentations to produce wine. Solid particles provide the yeast with essential nutrients and are, therefore, a determinant factor in alcoholic fermentation.

The main mechanisms underlying the impact of solids on fermentation kinetics have been deciphered. Nevertheless, further knowledge about grape solids is required to address several unresolved issues: (1) understanding solid composition and structure during fermentation and the changes in solid composition and structure throughout this process; (2) the bioavailability of nutrients should be investigated, with the definition of more appropriate criteria for characterizing the nature and properties of sludge and determining its efficiency; (3) understanding of the mechanisms by which yeasts take up sterols from solids for the maintenance of membrane structure and metabolism; and (4) improving the description of the impact of solids on aroma synthesis during fermentation.

From a practical point of view, the main challenge will be to optimize control strategies by taking management of solids into account together with other key control measures, such as the addition of oxygen and nitrogen.

\section{Literature Cited}

Alexandre H, Nguyen van Long T, Feuillat M and Charpentier C. 1994. Contribution à l'étude des bourbes: Influence sur la fermentescibilité des moûts. Rev Fr Enol 146:11-20.

Andreasen AA and Stier TJB. 1953. Anaerobic nutrition of Saccharomyces cerevisiae. I. Ergosterol requirement for growth in a defined medium. J Cell Compar Physl 41:23-36. 
Axcell B, Kruger L and Allan G. 1988. Some investigative studies with yeast foods. In Proceedings of the 20th Convention of The Institute of Brewing (Australia and New Zealand Section). pp 201209. Institute of Brewing, Sydney, Australia.

Battle JL, Boulet JC, Brugirard A, Dubernet M, Escudier JL, Moutounet M, Saint-Pierre B and Vernhet A. 1998. Chapter 19. Clarification, stabilisation des vins. In Enolologie: Fondements Scientifiques et Technologiques. C Flanzy (ed.), pp. 920-1001. Tec \& Doc/Lavoisier, Paris.

Bely M, Sablayrolles JM and Barre P. 1990. Automatic detection of assimilable nitrogen deficiencies during alcoholic fermentation in enological conditions. J Ferm Bioeng 70:246-252.

Bindon KA, Smith PA and Kennedy JA. 2010. Interaction between grape-derived proanthocyanidins and cell wall material. 1. Effect on proanthocyanidin composition and molecular mass. J Agric Food Chem 58:2520-2528.

Boulton RB, Singleton VL, Bisson LF and Kunkee RE. 1996. Preparation of musts and juice. In Principles and Practices of Winemaking. pp. 65-101. Chapman \& Hall, New York.

Brillouet JM, Romieu C, Schoefs B, Solymosi K, Cheynier V, Fulcrand H, Verdeil JL and Conéjéro G. 2013. The tannosome is an organelle forming condensed tannins in the chlorophyllous organs of Tracheophyta. Ann Bot 112:1003-1014.

Cabanis JC and Flanzy C. 1998. Lipides. In Enolologie: Fondements Scientifiques et Technologiques. C Flanzy (ed.), pp. 3-34. Tec \& Doc/Lavoisier, Paris.

Cartalade D and Vernhet A. 2006. Polar interactions in flavan-3-ol adsorption on solid surfaces. J Agric Food Chem. 54:3086-3094.

Casalta E, Aguera E, Liénard P and Salmon JM. 2009. Physical dynamics of sludges during wine fermentation in liquid phase. J Int Sci Vigne Vin 43:225-230

Casalta E, Cervi MF, Sablayrolles JM and Salmon JM. 2012. Effet combiné des niveaux d'azote assimilable et de bourbes: Nouveau parameter à prendre en compte pour la maîtrise de la fermentation alcoolique. Rev Fr CEnol 255:9-15.

Casalta E, Salmon JM and Sablayrolles JM. 2013. Interaction of assimilable nitrogen and grape solids on alcoholic fermentation under oenological conditions. Aust J Grape Wine Res 19:47-52.

Charrier F, Guérin L, Roland A and Samson A. 2013. Opérations préfermentaires. In "Les vins blancs de la démarche marketing à la vinification: Les clés d'un pilotage réussi." pp. 146-163, France Agricole, Paris.

Dahl C, Biemann HP and Dahl J. 1987. A protein kinase antigenically related to pp60 src possibly involved in yeast cell cycle control: Positive in vivo regulation of sterol. Proc Natl Acad Sci USA 84:4012-4016.

Daum G, Lees ND, Bard M and Dickson R. 1998. Biochemistry, cell biology and molecular biology of lipids of Saccharomyces cerevisiae. Yeast 14:1471-1510.

Davies-Colley RJ and Smith DG. 2001. Turbidity, suspended sediments and water clarity: A review. J Am Water Resour As 37:1085-1101.

Davin A and Sahraoui A. 1993. Débourbage rapide des moûts de raisin par flottation à l'aide de bulles générées au sein du liquide par dépressurisation. Rev Fr Enol 140:53-64.

Deytieux C, Mussard L, Biron MJ and Salmon JM. 2005. Fine measurement of ergosterol requirements for growth of Saccharomyces cerevisiae during enological fermentation. Appl Microbiol Biotechnol 68:268-271.

Duquene P, Samson A, Rapilly C, Bernet B and Salmon JM. 2014. Positionnement du décanteur centrifuge en vinification en blanc et rosé. Rev Fr Enol 266:8-16.
Eudier L, Samson A, Caille S, Aguera E, Bes M, Dangleville G, De Vlieger L and Salmon JM. 2011. Le décanteur centrifuge Alfa-Laval: Apport d'un nouvel outil pour le prétraitement de la vendange thermo traitée avant fermentation. Rev. Enol 138:18-20.

Feuillat M, Freyssinet M and Charpentier C. 1989. L'élevage sur lies des vins de Bourgogne. II. Evolution des macromolécules: Polysaccharides et protéines. Vitis 28:161-176.

Fornairon-Bonnefond C, Desmaretz V, Rosenfeld E and Salmon JM. 2002. Oxygen addition and sterol synthesis in Saccharomyces cerevisiae during enological fermentation. J Biosci Bioeng 93:176-182.

Groat M and Ough CS. 1978. Effects of insoluble solids added to clarified musts on fermentation rate, wine composition, and wine quality. Am J Enol Vitic 29:112-119.

Hanlin RL, Hrmova M, Harbertson JF and Downey MO. 2010. Review: Condensed tannin and grape cell wall interactions and their impact on tannin extractability into wine. Aust J Grape Wine Res 16:173-188.

Harris PJ, Henry RJ, Blakeney AB and Stone BA. 1984. An improved procedure for the methylation analysis of oligosaccharides and polysaccharides. Carbohydr Res 127:59-73.

Houtman AC and du Plessis CS. 1986. Nutritional deficiencies of clarified white grape juices and their correction in relation to fermentation. S Afr J Enol Vitic 7:39-46.

Jacquier N and Schneiter R. 2012. Mechanisms of sterol uptake and transport in yeast. J Steroid Biochem Mol Biol 129:70-78.

Jahnke L and Klein HP. 1983. Oxygen requirements for formation and activity of the squalene epoxydase in Saccharomyces cerevisiae. J Bacteriol 155:488-492.

Jollow D, Kellerman GM and Linnane AW. 1968. The biogenesis of mitochondria: III. The lipid composition of aerobically and anaerobically grown Saccharomyces cerevisiae as related to the membrane systems of the cells. J Cell Biol 37:221-230.

Jones RP and Greenfield PF. 1982. Effect of carbon dioxide on yeast growth and fermentation. Enzyme Microb Tech 4:210-223.

Kohlwein SD and Paltauf F. 1984. Uptake of fatty acids by the yeasts Saccharomyces uvarum and Saccharomycopsis lipolytica. Biochim Biophys Acta 792:310-317.

Kühbeck F, Müller M, Back W, Kurz T and Krottenthaler M. 2007. Effect of hot trub and particle addition on fermentation performance of Saccharomyces cerevisiae. Enzyme Microb Tech 41:711-720.

Le Fur Y, Hory C, Bard MH and Olsson A. 1994. Evolution of phytosterols in Chardonnay grape berry skins during last stages of ripening. Vitis 33:127-131.

Leber R, Zinser E, Zellnig G, Paltauf F and Daum G. 1994. Characterization of lipid particles of the yeast, Saccharomyces cerevisiae. Yeast 10:1421-1428.

Lorenz RT, Rodriguez RJ, Lewis TA and Parks LW. 1986. Characteristics of sterol uptake in Saccharomyces cerevisiae. J Bacteriol 167:981-985

Luparia V, Soubeyrand V, Berges T, Julien A and Salmon JM. 2004. Assimilation of grape phytosterols by Saccharomyces cerevisiae and their impact on enological fermentations. Appl Microbiol Biotechnol 65:25-32.

Reiner S, Micolod D and Schneiter R. 2005. Saccharomyces cerevisiae, a model to study sterol uptake and transport in eukaryotes. Biochem Soc Trans 33:1186-1188.

Reiner S, Micolod D, Zellnig G and Schneiter R. 2006. A genomewide screen reveals a role of mitochondria in anaerobic uptake of sterols in yeast. Mol Biol Cell 17:90-103.

Ribéreau-Gayon P. 1985. New developments in wine microbiology. Am J Enol Vitic 36:1-10. 
Ribéreau-Gayon P, Lafon-Lafoucarde S and Bertrand A. 1975. Le débourbage des moûts de vendange blanche. Connaiss Vigne Vin 9:117-138.

Rosenfeld E, Beauvoit B, Blondin B and Salmon JM. 2003. Oxygen consumption by anaerobic Saccharomyces cerevisiae under enological conditions: Effect on fermentation kinetics. Appl Environ Microbiol 69:113-121.

Roufet M, Bayonove CL and Cordonnier RE. 1987. Etude de la composition lipidique du raisin Vitis vinifera L.: Évolution au cours de la maturation et localisation dans la baie. Vitis 26:85-97.

Ruggiero A, Vitalini S, Burlini N, Bernasconi S and Iriti M. 2013. Phytosterols in grapes and wine and effects of agrochemicals on their levels. Food Chem 141:3473-3479.

Sablayrolles JM and Barre P. 1986. Evaluation of oxygen requirement of alcoholic fermentations in simulated enological conditions. Sci Aliments 6:373-383.

Saeman JF, Moore WE, Mitchell RL and Millet MA. 1954. Techniques for the determination of pulp constituents by quantitative paper chromatography. Tappi 37:336-343.
Smith SJ and Parks LW. 1993. The ERG3 gene in Saccharomyces cerevisiae is required for the utilization of respiratory substrates and in heme-deficient cells. Yeast 9:1177-1187.

Smith SJ and Parks LW. 1997. Requirement of heme to replace the sparking sterol function in the yeast Saccharomyces cerevisiae. Biochim Biophys Acta 1345:71-76.

Tesnière C, Delobel P, Pradal M and Blondin B. 2013. Impact of nutrient imbalance on wine alcoholic fermentations: Nitrogen excess enhances yeast cell death in lipid-limited must. PLoS ONE 8:e61645.

Tuller G and Daum G. 1995. Import of sterols into mitochondria of the yeast Saccharomyces cerevisiae. FEBS Lett 372:29-32.

Vernhet A, Bes M, Bouissou D, Carrillo S and Brillouet JM. Characterization of suspended solids in thermo-treated red musts. J Int Sci Vigne Vin. In press.

Vivas N and Cros M. 1991. Influence du contrôle de l'anaérobiose et de la température sur le cycle de croissance et le métabolisme des levures. Application aux cuves à remontage séquence. Progrès Agricole et Viticole 108:163-165. 